Baym, N. K. (1995), The Performance of Humor in Computer-Mediated Communication. Journal of Computer-Mediated Communication.

Publisher's official version: http://dx.doi.org/10.1111/j.1083-6101.1995.tb00327.x Open Access version: http://hdl.handle.net/1808/8710

[This document contains the author's accepted manuscript. For the publisher's version, see the link in the header of this document.]

\title{
The Performance of Humor in Computer-Mediated Communication
}

\author{
Nancy K. Baym \\ Assistant Professor \\ Department of Communication \\ Wayne State University \\ http://www.comm.wayne.edu/NancyBaym.html \\ Journal of Computer Mediated Communication \\ September, 1995
}

Author address: 585 Manoogian, Wayne State University, Detroit, MI 48202

email: nbaym@cms.cc.wayne.edu

\section{Paper citation:}

Baym, N. K. (1995), The Performance of Humor in Computer-Mediated Communication. Journal of Computer-Mediated Communication, 1: 0. doi: 10.1111/j.1083-6101.1995.tb00327.x

\begin{abstract}
:
There has been very little work on humor in computer-mediated communication. Indeed, the implication of some CMC work is that the medium is inhospitable to humor. This essay argues that humor can be accomplished in $\mathrm{CMC}$ and can be critical to creating social meaning on-line. The humor of the Usenet newsgroup rec.arts.tv.soaps (r.a.t.s.), which discusses soap operas, is analyzed. The method combines user surveys with message analysis to show the prevalence and importance of humor in r.a.t.s. Close analysis of five exemplary humorous messages shows how the group's humor arises from the juxtaposition of close and distant readings of the soap opera, which place the participants in close relationships to one another, and distance them from the soap opera's writers and producers. Group solidarity is also created as participants draw extensively on previous messages to ground their own humor. Humor is also shown to be a primary mechanism for the establishment of individuality, as participants combine the shared meanings and play with the shared parameters of the group in idiosyncratic ways.
\end{abstract}




\begin{abstract}
There has been very little work on humor in computer-mediated communication. Indeed, the implication of some CMC work is that the medium is inhospitable to humor. This essay argues that humor can be accomplished in CMC and can be critical to creating social meaning on-line. The humor of the Usenet newsgroup rec.arts.tv.soaps (r.a.t.s.), which discusses soap operas, is analyzed. The method combines user surveys with message analysis to show the prevalence and importance of humor in r.a.t.s. Close analysis of five exemplary humorous messages shows how the group's humor arises from the juxtaposition of close and distant readings of the soap opera, which place the participants in close relationships to one another, and distance them from the soap opera's writers and producers. Group solidarity is also created as participants draw extensively on previous messages to ground their own humor. Humor is also shown to be a primary mechanism for the establishment of individuality, as participants combine the shared meanings and play with the shared parameters of the group in idiosyncratic ways.
\end{abstract}

\title{
Introduction
}

Computer-mediated communication $(\mathrm{CMC})$ is often seen as a means of distributing information, of increasing organizational efficiency, of creating electronic democracy, or of challenging traditional hierarchies. It is rarely seen as a means of making people laugh. Yet CMC can be, and is, used as a forum for humorous performances. With the exception of some work on the use of computers to distribute jokes (Fox, 1983) and Danet, Wachenhauser, Bechar-Israeli, Cividalli and RosenbaumTamari's work on wit and humor in on-line parodies of Shakespeare on Internet Relay Chat (Danet, et al., 1995, this issue), little if any work to date has examined the role of humor in CMC.

Analysis of humor is important because CMC research has been slow to address the formation of group identity and solidarity, though such phenomena occur in on-line groups and are negotiated, in part, through humor. Rheingold's (1993) book on The WELL, an electronic bulletin board in Northern California, provides one rich description of a "virtual community." Wilkins' (1991) description of an electronic meeting group also provides evidence of community formation in $\mathrm{CMC}$, yet neither of 
these works have provided more than anecdotal evidence on how solidarity and group identity emerge in $\mathrm{CMC}$, and neither discuss humor.

Analysis of humor can also contribute to the growing line of work on the development of individual identity in CMC. Generalizing from initial interactions, many CMC scholars have argued that the lack of visual and auditory information in computer-mediated talk strips cues to status, appearance, identity and gender (Cheseboro \& Bonsall, 1989; Kiesler et al., 1984; Raymond, 1991). Some hold that this inevitably reduces the communicators to anonymity. Others have shown that identity can be established in CMC (e.g. Baym, 1993; Myers, 1987; Reid, 1995; Walther \& Burgoon, 1992). Identity cues have been analyzed in explicit self-descriptions, message headers and signatures, and other message features, but have not been linked to humor.

This paper shows how humorous performance can be used to create group solidarity, group identity, and individual identity in CMC. It does so by exploring humor in a computer-mediated group distributed through Usenet which discusses soap operas. Usenet is a computer network distributed primarily through the Internet. It hosts several thousand discussion groups called "newsgroups." One of the most successful of these is rec.arts.tv.soaps, also known by its acronym r.a.t.s. As the name implies, r.a.t.s. participants discuss television soap operas, generating thousands of messages every month. Each message, or "post," is in the form of an electronic letter, distributed to all computers on the network and available for reading by anyone with an account that offers Usenet access. Most of the participants in r.a.t.s. are female students or employees of computer-related organizations. When r.a.t.s. was finally divided into subgroups by television network in 1994 there were as many as 10,000 messages exchanged each month.

In what follows I integrate theories of conversational humorous performance and soap opera narrative with analyses of humorous messages to show how r.a.t.s. humor draws on, distorts and amplifies the narrative of the soap, and how this humorous reframing of the narrative serves as a locus of group solidarity and emergent individuality. I also demonstrate how humor can be framed without the nonverbal cues of face-to-face interaction. 


\section{Humorous Performance}

CMC has generally been understood through a "talk" metaphor, which compares on-line interaction to face-to-face conversation. While CMC is obviously not talk, it is in many ways more like conversation than writing because it is interactive, relatively spontaneous and generally unplanned (see Ferrera, Brunner, \& Whittemore, 1991). Because of these similarities, the work on humor in conversation provides a more appropriate starting point for the analysis of CMC than the vast body of work on humor in literature.

Most theories of humor argue that it arises out of sudden incongruity or what Oring (1992) calls "appropriate incongruity." In humor, incompatible frames are juxtaposed, resulting in "a bifurcated logical process" (Palmer, 1994, p. 96). Humorous shifts in perceptual frame cause us to simultaneously recognize "ambiguity, inconsistency, contradiction and interpretative diversity" (Mulkay , 1988, p. 26). Not all sudden incongruities nor all instances of humorous forms are taken to be funny. As Chiaro puts it, "the concept of what people find funny appears to be surrounded by linguistic, geographical, diachronic, sociocultural and personal boundaries" (1992, p. 5). In other words, humor cannot be separated from the group in which it is used or the individuals who participate. It is embedded in shared knowledge, shared codes and shared emotional significances which provide its meanings and determine its appropriateness (Chiaro, 1992; Oring, 1992; Palmer, 1994).

Though many analyses of humor have focused on its forms (e.g. riddles, puns, and so on) (Chiaro, 1992), other analyses have focused on humor as situated performance. Bauman and Briggs (1990, p. 73) define performance as:

a specially marked, artful way of speaking that sets up or represents a special interpretive frame within which the act of speaking is to be understood.

Performance puts the act of speaking on display -- objectifies it, lifts it to a degree from its interactional setting and opens it to scrutiny by an audience.

Performance ... licenses the audience to evaluate the skill and effectiveness of the performer's accomplishment.

Humorous performances carry meanings which are "only discernible in situations of performance in relation to particular tellers, audiences, settings and interactions" (Oring, 1992, p. 31). This view of humor highlights two dimensions of the discourse -- 
the incongruities it evokes and the socio-cultural situation which give those incongruities their meaning and humorous impact.

A third issue in the analysis of humorous performance is how it is framed as open to evaluation. The cues used to frame performances in face-to-face interaction include "a wink, gesture, posture, style of dress, musical accompaniment ... English aspiration and vowel length" (Hymes, 1986, p. 62). Humor cues indicate that the appropriate frame is one of play rather than seriousness (Mulkay, 1988) and include conventional openings (e.g. "did you hear the one about..."), tones of voice, facial expressions, body posture, and laughter (Palmer, 1994). Given that so many of these cues are nonverbal, how one would frame a message as a performance in CMC is not altogether apparent; the computer medium can eliminate these very cues (Kiesler, Siegel, \& McGuire, 1984; Sproull \& Kiesler, 1991).

However, Palmer (1994) argues that the key element of a humor cue is what transgresses normalcy in the context. Thus, if there is any kind of normalcy, as there is in $\mathrm{CMC}$, then transgressions, and hence humorous performative cues, are possible. Furthermore, humor cues can be incorporated within the humor itself. Mulkay argues that an interpretive reversal may be cue enough to "generate the terminal response required by humor -- namely laughs and smiles" (1988, p. 54). In r.a.t.s., as the analyses will show, the cues which frame performance are reinvented, borrowed, or integrated fully into the humor itself.

Finally, performance-oriented theories posit that humor serves at least four social functions. It aids self presentation, facilitates the creation of common understanding, and helps generate solidarity and group identity (Norrick, 1983; Palmer, 1994). Humor also expresses the complexities and problems of the social world. For while humor is by definition non-serious, "informal humour is frequently regarded by participants as a way of expressing serious intent and of conveying serious information without appearing to do so"' (Mulkay, 1988, p. 69).

\section{Engaging the Soap Opera Narrative}

The incongruities and socio-cultural meanings in r.a.t.s. humor are based primarily on the soap opera text and the participants' interpretation of that text. Understanding r.a.t.s. humor and its role in generating solidarity and identity thus requires analysis of the genre and how it is engaged by its audience. Soap opera plots 
are designed as arcs which develop over periods of months. A single episode involves multiple storylines and resolves none. Each episode engages viewers in part by implying more meanings than are needed for the day's plot development. Implied meanings might suggest a character's true nature, what could happen in the days, weeks and months to come, what should happen, or what a scene's ramifications throughout the soap's fictional community will entail. It is this "overcoding" which is at the heart of viewer engagement (Allen, 1983, 1985).

In order to infer these meanings, soap viewers must have several competencies. Allen (1983) elaborates four codes viewers must know in order to read soaps. "Videocinematic codes" decipher the logic behind the filming. If the camera movement is changed, for example, a competent soap viewer will understand that this signals something important. "Generic codes" of the soap opera form include the use of time, space, style of acting, and multiple intersecting narratives. "Intertextual codes" are those which draw on other genres and texts, as when soap operas have whodunnit mysteries or secret wives as in Jane Eyre. Finally, "ideological codes" draw on the common frames of experience which allow for evaluation of the stories. The primary pleasure of soap opera viewing is in using knowledge of these codes to generate unstated meanings. Because different viewers can make very different sense of the same episode, the pleasure of soap discussion often stems from pooling and debating these interpretations.

Because decoding meaning depends on analysis of the genre's formal conventions as well as its content, viewers must watch soap operas in both close and distanced ways simultaneously. In close readings, viewers operate within the story's terms, accepting the characters and settings as real and suspending disbelief. In distant readings, viewers step outside the story world to view it as a constructed fiction, Geraghty writes, "soaps invite the audience both to enter intimately into a fictional world and to stand back and view with dispassion the formal conventions through which that world is constructed" (1991, p. 10). While soap writers and directors often depend on viewers' distanced readings of their show to generate the meanings, distanced viewing also generates viewer criticisms with which these producers might be less pleased. Competent viewers continually assess the shows' ideological messages, story construction and, above all, realism, often finding them wanting (Ang, 1985; Liebes and Katz, 1989; Hobson, 1989; Seiter et al, 1989). Viewers also critique their own involvement, contemplating the contradictory pulls toward pleasure and cynicism 
(Ang, 1985; Liebes \& Katz, 1989; Brown, 1994). The incongruity between close involvement with the narratives and reasoned criticism of their construction is the source of most humor in r.a.t.s., and provides humor with its power to generate group solidarity.

\section{Methods}

This study draws on an ethnographic analysis of r.a.t.s. done over a two year period. I collected posts to the group systematically for ten months in 1992. In that time I collected 32,308 messages, $92 \%$ of the total public discourse during those months. I also interviewed group members both formally and informally, face-to-face and electronically. I posted two sets of open-ended survey questions to the group. Response rates to surveys posted to online newsgroups is generally low, as people feel no obligation and have no incentive to respond. Jindra (1994) received 33 responses to his online survey of Star Trek fans; in a study of the newsgroup rec.music.rem I obtained 24 responses. In this study I received 51 responses. Beyond the content of their postings, responses to posted surveys are the only way to access participants' perspectives, but the low response rate means that this data cannot be generalized to all group members' experiences. However, these participants' comments enhance and compliment the phenomena observed in the messages and thus should not be dismissed. I also collected statistical information about events and participants, including how many people participated, how many messages were posted, and other macro-level information.

The corpus of 32,308 messages is too large for analysis of the role of humor in the group. I thus examined the discussion of only one storyline from the soap opera All My Children $(A M C)$. I selected messages from the first rumors of its inception till the last mention of its events. Unlike other ways of sampling, such as episodically or for predetermined time-periods, this method retained the coherence of the messages for group participants. I chose a storyline which centered on the activities of one initiallyunknown character named Carter Jones, a brilliant and smooth wife-beater who came to town to get even with his ex-wife for sending him to jail.

Carter, played by John Wesley Shipp, was on the show for 4 months. In this time he threw a number of lives into upheaval, first by stalking his ex-wife Galen (a.k.a. Maggie), then beating a young woman named Dinah Lee who tried to befriend him, and later by kidnapping Natalie Dillan, wife of Trevor and mother of Timmy. Among the storyline's appeals for this research was that participants in the group had very 
mixed feelings about it. For while Carter was an intriguing character, and participants generally liked Shipp, the storyline was unusually violent toward women and upsetting. It thus embedded contradictions which could stimulate humor or render it inappropriate. It was also a highly-discussed storyline. There were 524 messages in the corpus mentioning the Carter storyline. The week in which it climaxed was one of the highest traffic periods in the ten-month period during which I collected messages. Furthermore, Carter's stay in $A M C^{\prime}$ 's fictional town of Pine Valley was bounded by a clear entry and departure, both of which were contained within my data, giving the story obvious logistical appeal.

I approach these messages in two ways. I begin with an overview of the status of humor in r.a.t.s. and in the Carter Jones corpus, discussing its importance, frequency, participants, degree of responsivity, and critical tone. I then offer five close analyses of specific performances in order to elucidate the originality of each performance, the highly detailed social meaning embedded in each performance, and the ways humor navigates the participants' relationships to one another and to the soap opera.

\section{Overview of Humor}

Humor is a defining feature of r.a.t.s., as I found in my own experience as a participant and as is described in survey responses. Most respondents agree that there are few posts (or posters) more appealing than those which make them laugh, as this sampling of quotes indicates:

I like any post that's thoughtful or humorous (Jane, November 27, 1991)

I prefer humorous posts (Zoey, December 1, 1991)

A sense of humor seems to be the strongest attraction (Carrie, December 3, 1991)

I suppose the posts I enjoy the most (about r.a.t.s) are the ones that make me laugh (Joan, December 3 1991)

Humor and originality are two key ingredients of a good post (Michelle, December 13, 1991)

Humor marks quality posts, individualized posters, and is a central appeal of the newsgroup. 
One might think that the gravity of the social issues raised by the Carter Jones storyline and the participants' discontent with the storyline would lead them away from using humor. This was not the case at all. $27 \%$ of the 524 posts which mentioned the storyline contained at least one funny element, as measured by explicit responses recognizing funny performances, use of cues associated with humor, and my own sense of humor as a group participant. Not only was there a lot of humor, it came from many participants. Of the 128 posters who participated, $41 \%$ used humor at least once.

$60 \%$ of the humor occurred in posts which responded to other posts. This rate of responsiveness is somewhat less than the overall distribution of posts in r.a.t.s., $72 \%$ of which were responses (Baym, 1994). Humor is thus somewhat more independent than most discourse, but is still primarily stimulated by others, especially by others' humor. This finding echoes those on humor in conversational contexts (Chiaro, 1992; Mulkay, 1988; Norrick, 1993). Two tentative conclusions can be drawn from this finding in this computer-mediated context. The fact that humor is slightly less responsive than posts in general could mean that humor is more individualizing than many other messages. That so much of it is responsive, however, could mean that humor is an important way in which participants connect to one another and create the group's social environment. By using an earlier post as a launching pad for fun, a poster engages the other in a game, enhancing the group's sociable and playful nature.

Most of the humor in the discussion of this storyline was critical, supporting Mulkay's argument that humor relies upon problematic social meaning. Three-quarters of the humorous posts were negative, criticizing the storyline, characters, writing, props, and other aspects of the soap. This suggests that the distanced readings were particularly fertile ground for humor, especially when they challenged close involvement.

\section{Close Analyses of Humorous Posts}

This overview indicates the prevalence and value of r.a.t.s. humor, but cannot convey the rich variety across performances. As Bauman argues, "all performances are not the same, and one wants to be able to appreciate the individuality of each, as well as the community-wide patterning of the overall domain" (1975, p. 302). Without close examination of individual performances one is less likely to grasp humor's "interpersonal and social dimensions [which] requires an investigation of their real-life contexts" (Norrick, 1993, p. 2). The posts selected for analysis are of two types: retellings 
of episodes and responses to other posts. Messages in r.a.t.s. often touch on more than one storyline. In most cases the analyses below present only those sections of the post which focus on the Carter Jones storyline. With the exception of these deletions, posts appear exactly as they did when they were posted, including quotation, spacing, line breaks, (mis)spelling and grammar.

\section{$\underline{\text { Updates }}$}

One of the more intriguing finding about the humor in this group is how much of it is concentrated in the "updates." These posts, which retell one day's events on the soap, account for only 3\% of the total messages about AMC, but contain $21 \%$ of the humor. One might think that updates would only repeat events, as is often the case in newspaper soap updates. However, these updaters are not just reporters, they are storytellers. Brown (1990) compares soap retellings to traditional orally-transmitted narratives, suggesting that experienced retellers stylize their performances to provide entertainment to the listeners. Retelling thus becomes an opportunity for performance. The updates on r.a.t.s. are stylized transformations of the soap opera; All My Children becomes a resource out of which further entertainment is built.

Work on conversational storytelling has shown that stories involve at least three components (e.g. Polanyi, 1982). The referential component describes the events. The interactive component entails responsivity to one's listeners; conversational stories are addressed to specific interlocutors and the telling is negotiated with those interlocutors. The evaluative component involves the positions the teller takes toward the referential component. Evaluation is conveyed through intensifiers, qualifiers, explicit references to emotion, quoted speech, comparators, and repetition, among other speech cues. Labov (1972) argues that the evaluative component emphasizes deviation from the norm, thus making the story's relevance to the interactants clear.

In the case of r.a.t.s. updates, the relevance is obvious. The readers are already involved in the narratives under discussion (otherwise they wouldn't be reading the group). If they missed the show, they are anxious to know what developments there were. Updates are considered so important in r.a.t.s. that a system has been developed in which pre-assigned updaters take responsibility for one day's episode each week. Updates are continually requested by those who don't realize that an update will be posted within a few days. From a relevance perspective, then, a simple referential report could suffice. 
However, there are several reasons for retellers to provide an evaluative component despite this. As Brown points out, the tellers gain pleasure from providing stylized retellings which entertain in their own right. This is a good thing for readers who have missed episodes, as it means that updates offer them some of the drama which draws them to the show as well as storyline developments. Evaluation can also help the readers to infer further meanings than the report alone would provide. Furthermore, many of the updates' readers have already seen the episodes they retell. For them, a straight report is completely boring. The evaluative component is the only reason to read, as is evidenced by these participant comments:

To tell you the truth, the updates are more fun than the shows ... It adds so much more to the shows (Jamie, October 1, 1993)

I rarely read the updates indepth since I watch the show for myself, but for some, r.a.t.s. is the only means of keeping up with the storylines. The updaters' personal comments are of more interest to me than the updates themselves (Carrie, December 3, 1991)

Evaluative retellings bring tellers' perspectives to bear on the events they report, as they incorporate their own inferred meanings into the narrative's explicit events. Updates become an elaborated version of the show in which the original events are combined with the posters' insight, enabling informed viewers to compare interpretations. I turn now to two updates, written by regular $A M C$ updaters. In them we can see that humor arises in interplays between the referential and evaluative components, close and distant readings, accepting and critical responses.

Margie's update. This first post (July 31, 1992) is by the Thursday updater, a woman named Margie. Margie is notable for writing the longest messages in the group. This update, for instance, was 308 lines in its entirety (compared to the 27-line average for most posts and 144-line average for updates). This update was written early in the storyline, when Carter first appeared in town and began stalking Galen (Maggie). Margie begins the update, as she begins all her updates, with a heading indicating the date of the show and brief titles summarizing the storylines featured in that day's episode:

AMC Update, Thursday July 30 th

-..

Featuring: A fashion base hit for Angelique (FINALLY!) 


\author{
Ursula the parakeet (YAWN!) \\ Adam plays Stuart, argyle sweater and all! \\ One Big Happy Family
}

Among other storylines, she identifies that of "Ursula the parakeet," into which she asserts, from the very beginning, her own evaluative voice. By compressing the day's events into one line she selects what she takes to be the story's point. In this case, her focus on the narrative device of the bird trivializes the soap writers' emphasis on Carter's menace and Galen's terror. Her explicit commentary, "YAWN!" is bracketed with parentheses and emphasized with capitalization and an exclamation point, each of which represents a digression from the norm within the post and the group, cueing humorous performance. Bracketing is a common way to mark humor, especially in updates. Margie relies upon the convention in her retelling of "Ursula the Parakeet," where her square brackets mark movement between close readings and distant, usually critical, commentary.

The retelling begins with repetition of the title, this time expanded to identify the main characters involved. After separating the title from the retelling with a horizontal line, she launches into a detailed version of the day's events:

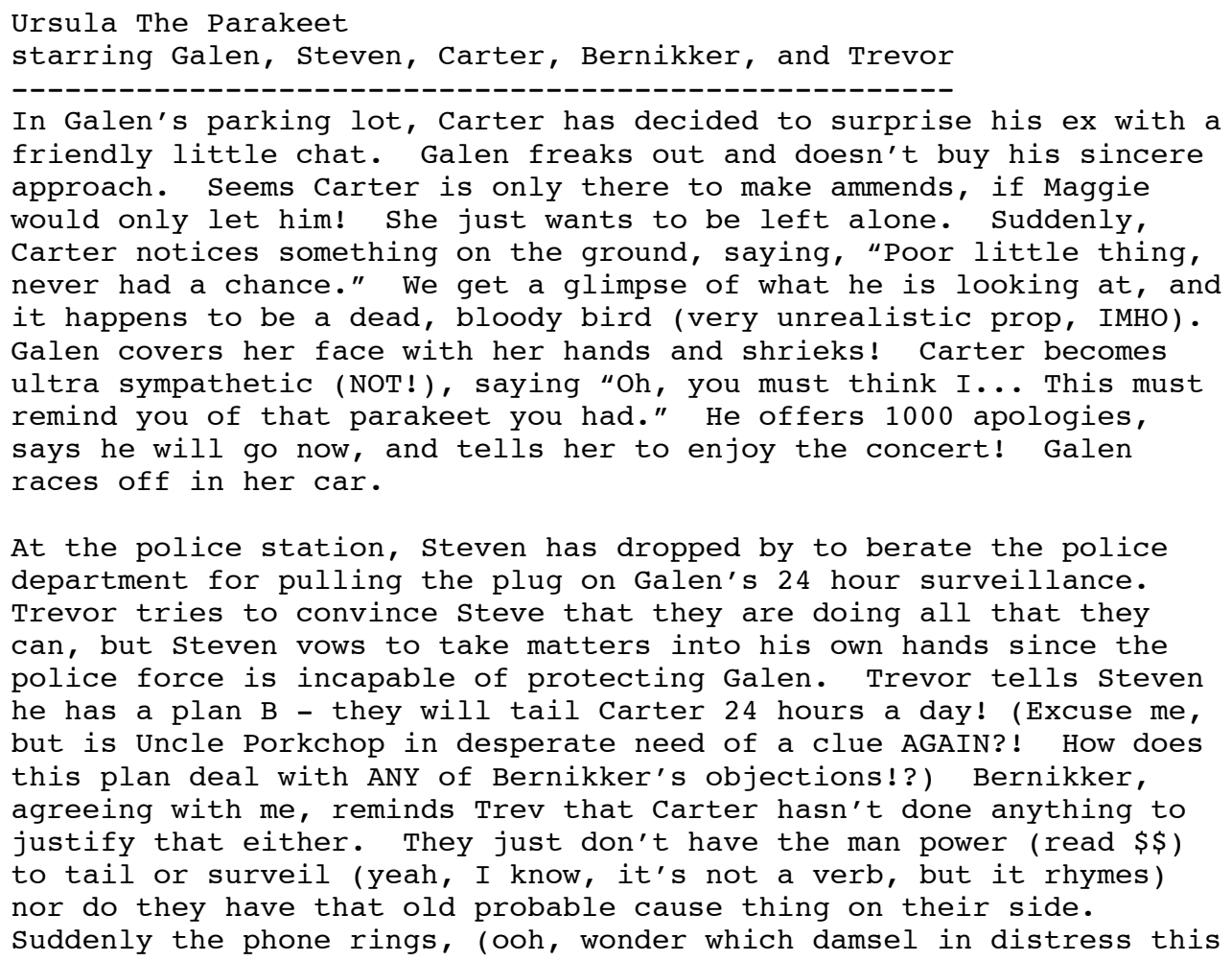


is?? NOT!) and Bernikker screams "WHAT?" and announces, "It's Galen Henderson." (Goodness, I'm sure glad he gave us her full name; for a minute I might have thought it was some other Galen. I mean, the name is sooo common. Writers, you make this dude look as smart as a $\log !)$

Seconds later, Galen, Steven, and Trevor are in the parking lot where the encounter took place. Galen explains to the two of them the significance of the dead bird. Seems she had a parakeet named Ursula (Galen's reason for the name: "She just looked like an Ursula to me!") and Carter hated it's stupid chattering. (Guess she and Ursula had a lot in common.) One day when she came home, Carter told her Ursula had flown away while he was cleaning the bird cage. 2 weeks later, Galen found Ursula who hadn't flown anywhere. (They spared us the stupid gory details.) Trevor goes off to look for the bird remains which are gone. Steven asks Galen if she still wants to go to the concert after all that has happened. She is insistent on going especially since Carter expects to have intimidated her into staying home. She doesn't want him to think he can isolate her from her friends and make her a victim again! Go, Galen!!! So who's ready for some Mahler, she asks? Steven looks at her and smiles, admiring her spunk. Trevor looks at her like she is insane!

The three of them go to the concert together (Excuse me, but what happened to Trevor's LIFE?) and stand around worrying about Carter showing up. Galen is the most calm of all of them! Steven excuses himself to go beg Brooke (see One Big Happy Family) to fire Carter. He informs her that she has a "whacko" working for her. She nicely but firmly tells steven she can't help him out. He thanks her for her "overwhelming" sympathy. (For real! Has she forgotten Gil, the rapist, and how she felt when no one would believe her! And when her own husband wouldn't get him out of their house!)

Shortly after Steven returns to Trev and Galen, he excuses himself AGAIN! This time, he has spotted Carter going upstairs. No one else has noticed. Galen wonders to Trevor where Steven has gone, and Trevor guesses the bathroom. Trevor turns out to be right, but Steven doesn't need to take a whiz; he is hiding out, ready to pounce on Carter! When Carter arrives, Steven grabs him, shoves him, and suggests they talk. Carter feigns ignorance, but steven slams him around until he remembers what they have in common. Carter says whatever steve wants to talk about must be pretty important for him to leave Galen all alone, she's quite a looker and Dr. Hamil is a lucky man. Steven shoves him again and says Carter is NOT lucky. "This game you're playing, it ends NOW!" And as the camera cuts, Steven has Carter by the lapels, up against a bathroom wall...

Margie uses several evaluative devices to enhance the performative and evaluative quality of her retelling. The use of titles provides foreshadowing. Quoted speech, exclamation points, use of the present tense, and descriptive action words like "races" invest the retelling with some of the dramatic force of the original show. Her use of contrastive parallelism ("Steven looks at her and smiles... Trevor looks at her like she is insane") conveys the video-cinematic information an actual viewing would carry, 
implying two potential story outcomes -- Galen's triumph or demise. Repetition of letters, as in "sooo," add paralinguistic information to her style. These elements of the retelling link the update closely to the soap episode by bringing the drama of the latter into the former and providing the detailed information which allows her readers to infer multiple coded meanings.

Her humor occurs almost entirely in her bracketed reactions, and is almost entirely critical. Here she turns from close to distanced involvement and shifts her voice from speaking for the story to speaking for herself. Her criticisms are directed at five targets -- the props, the storyline's worth, the characters, the writers, and herself, each of which were common targets of criticism in others' humorous posts as well. Each of these criticisms entails attributions as to who is at fault, and many entail modes of address and self-references which specify both recipient and updater persona.

The dead bird, she tells us, was a "very unrealistic prop, IMHO" (In My Humble Opinion), a comment addressed to the readers, referencing herself, and faulting the prop department. She ridicules the dead bird plot and aligns herself with her readers using a plural "us" in the phrase "they spared us the stupid gory details." "They" here faults the writers, whom she seems to hold accountable for this "stupid" development. She pokes fun at the policeman, Trevor ("Uncle Porkchop" -- a nickname used on the show itself), who is suddenly spending all his time guarding Galen: "Excuse me, but what happened to Trevor's LIFE?" Trevor is also mocked for being "in desperate need of a clue AGAIN" for failing to accommodate his protection plan to the police chief's (Bernikker) objections. Galen is also the target of her criticism as she compares Ursula's "stupid chattering" to Galen's: "guess she and Galen had a lot in common." Rather than faulting the writers per se, Margie here faults the characters, suggesting simultaneously close yet critical reading.

The predictability of soaps is another of Margie's targets. When the telephone rings just as Bernikker and the other police are discussing Galen, she writes "ooh, wonder which damsel in distress this is?? NOT!" Here both the obviousness of the caller and Galen's status as a female victim are mocked. When Bernikker identifies the caller by her full name, although it is an unusual first name, Margie explicitly addresses her comments to the writers, placing blame and shifting recipiency: 
Goodness I'm sure glad he gave us her full name; for a minute I might have thought it was some other Galen. I mean, the name is sooo common. Writers you make this dude look as smart as a log!

Her criticisms here target two common soap opera phenomena, the use of names which border on the absurd, and the predictable narrative technique of bringing off-screen characters into a scene whenever they are discussed by those present. The humor thus demonstrates her understanding of the generic code of soaps. Her invocation of them implies an assumed similarity with her readers who, she implies, will share this competence and understand the sarcastic humor.

The writers are not the only ones who use silly tricks, however, as Margie recognizes by mocking herself. After using the phrase "to tail or surveil" she writes "yeah, I know, it's not a verb but it rhymes." Here she explicitly draws attention to the performative quality of her writing (she is seeking to rhyme for effect) and the evaluative responses she expects, as she anticipates her readers' complaints ("yeah, I know"). As Norrick (1993) points out, self-effacing humor serves the self-presentational goal of creating a positive face, for it shows that the speaker has the admired personality trait of being able to laugh at her own shortcomings. She is also drawing attention to herself and her role as updater, enhancing her identity as an individual with her own characteristics and voice.

One way in which Margie's humor enhances her alignment with the other participants is her use of the term "us." She further enhances solidarity through her assumption that her readers share her soap viewing competencies. Margie also invokes common knowledge, drawing on her readers' knowledge of $A M C$ history and previous discussions on r.a.t.s. When she writes that Trevor needs a clue "AGAIN," for example, she makes an implicit reference to an earlier storyline in which Trevor failed for several months to notice that his "wife" was an impostor (the real wife, Natalie, having been thrown down a well by her demented sister Janet). The storyline, which many participants in r.a.t.s. felt lasted too long, was discussed so much that any reference to "the well" now implies a never-ending dull storyline. Discussion during the well was especially funny. By comparing Trevor's behavior now to his behavior in that storyline, she invokes for continuing participants both the well storyline and the humor with which participants surrounded it. Similarly, her use of the phrase "damsel in distress" to describe Galen reinvokes the group's ongoing discussions of this theme. 
In sum, much of Margie's humor can be seen as occurring in the shift from close readings of the soap, which focus on dramatic events, to distanced readings, which point out the show's shortcomings. Her humor gains its force in the contrast between the reality which fans grant soap operas and the absurdity they recognize within it. Margie's humor thus brings to the fore the incongruities between the soap world and the fans' participation in it. She provides a service for her readers by retelling the show, which in a sense sets her apart from them and enhances her individuality. However, her distanced comments and transformations of prior discussion position her close to her readers, implying they are collaborators who share a discourse history, $A M C$-specific knowledge, and genre competencies.

Lyle's update. While the themes in Margie's humor are replicated in other humor posts, her style is highly distinctive, a point which becomes clear when she is contrasted with another updater, who also has a highly personalized style. Lyle is explicitly recognized within the group's discussions as especially funny. He is among the most well-known of the posters, and was one of the few posters survey respondents mentioned by name. His identity within the group is created largely through his humor. While he does share some information about himself with the group, he remains in many ways what another poster described as "a very private person." Despite explicit urgings, for instance, he was one of the few regular posters who chose not to participate in a yearbook compiled by participants. The same person who describes him as private goes on, however, to add that he is "one of the wittier and more adventurous posters" and describe him as "great" (Ellen, November 27, 1991). Another poster, himself a recognized funny fellow, also identifies Lyle explicitly with humor:

What makes a r.a.t.s. poster successful is a sense of humor, which many of the AMC posters have, especially Lyle and Granma, who are my two favorite people to read. They also have terrific imaginations. (Brian, December 3, 1991)

However, Lyle is one of the few $A M C$ / r.a.t.s. participants who has active and vocal detractors. The conflict between Lyle and some of the other participants may lie partly in racial and gender conflicts. While r.a.t.s. is comprised primarily of white women, Lyle is an African-American man. Though this may be a rich avenue for further analysis I avoid it here for two reasons. First, to do these issues justice would require more elaboration than the scope of this paper warrants. Furthermore, I am wary of attributing his behavior to either gender or race; there is more to Lyle than his status as a black 
man. I thus limit my analysis of the controversy surrounding him to those problematic elements of his update which relate directly to issues of solidarity and identity.

This update of Lyle's (October 2, 1992) begins with a copyright logo and the same elaborate heading format with which he begins all his updates. Like Margie, he uses titles to foreshadow the day's events. However, his titles "Carter finalizes plans to kill Porkchop and frame Galen" and "DynaHo accepts a dinner date with Psycho," focus on central events rather than props, and while evaluation is seen in his use of character nicknames, his titles are not critical. His style is remarkably different from hers in other ways as well:

(c)

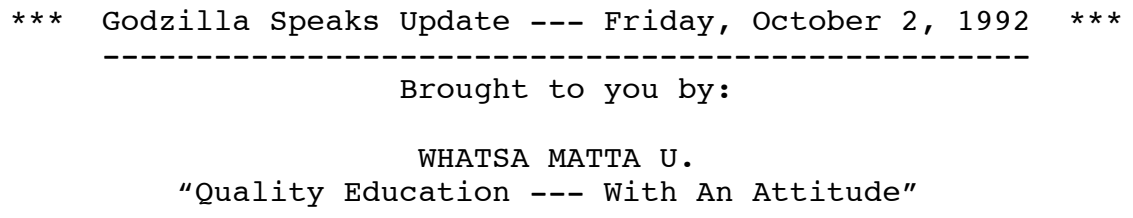

Not [ love the nickname, Claudette ], distraught over her lack of eyesight, has to deal with a rapidly-becoming-unhinged-just-fired-fromTempo Carter, who mini-flips ("What? Another one of those (sneer) 'liberated' women??!") after Not declares that she can take care of herself despite the handicap. She also declines a "Trevor's having an affair w/Galen" gambit, holding course in the storm. Carter bops to the lobby and steals Galen's purse in prep for the set-up.

Meanwhile, across town, DynaHo [ she's cute, Sue, not gorgeous ] has a heart-to-heart w/Myrt about Mahatma's warnings against Carter. Myrt 


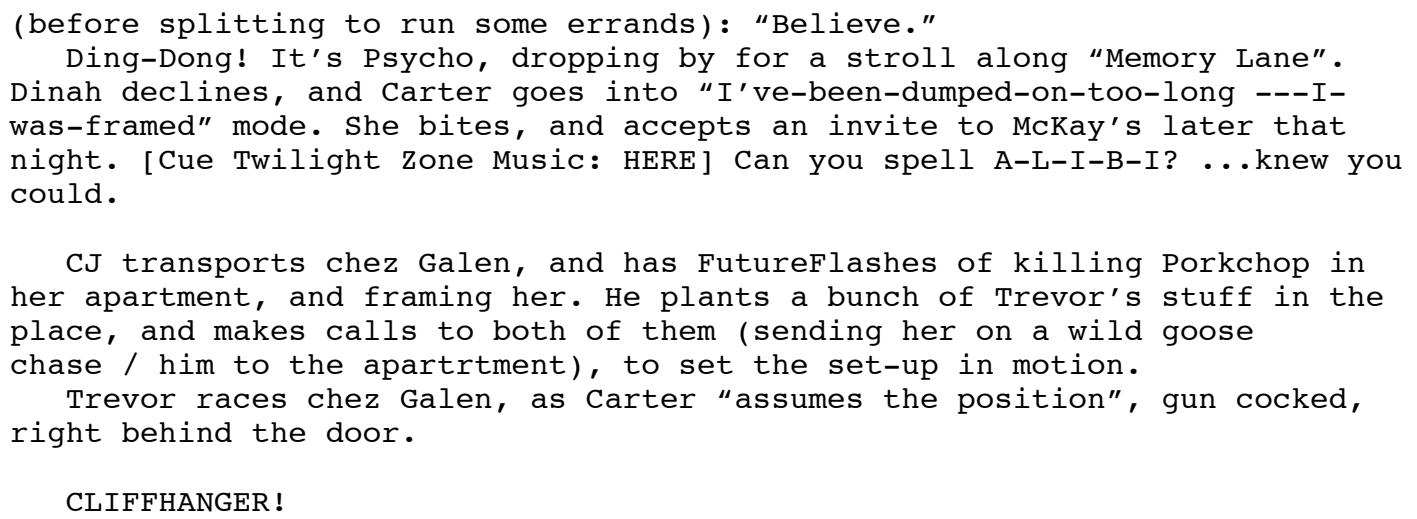

Like Margie, Lyle uses the devices of quoted speech and square-bracketed commentary to bring an evaluative dimension to his retellings. One use of the brackets not seen in Margie's post is to address specific r.a.t.s. participants. He uses the punnickname "Not" for Natalie, which indicates that Kate Collins, who originated the role, had been replaced by a new actress, Melody Anderson. He then uses brackets and, within them, commends the nickname's originator, Claudette. In this case he is facilitating Claudette's persona by giving her credit for originating the clever name. Later he uses brackets to inform another poster, Sue, that her assessment of the actress playing DinahLee (whom he calls "DynaHo" in another use of nicknames) as "gorgeous" was incorrect; she is merely "cute." The tendency seen here to claim authority over the other posters on matters of opinion is an attribute which some participants find unpleasant in Lyle's posts. He is developing his own "expert" persona, but in so doing is diminishing the value of other's interpretations, sacrificing group solidarity for individual identity.

Lyle also uses square brackets to insert other pop culture genres into the retelling. He indicates an ominous part of the show with the bracketed phrase "Cue Twilight Zone music: HERE" He follows this with a reference to another television show, Mr. Roger's Neighborhood: “Can you spell A-L-I-B-I? ... knew you could." Interestingly, this appropriation of other genres is a common way to create humor on r.a.t.s.; $18 \%$ of the humorous posts used this device. This suggests that the range of social meanings on which posters draw to create humor expands into areas of popular culture beyond the soap opera, particularly television culture. When Lyle and others index other television shows they broaden the shared understandings relevant to the community and expand the basis of the group's solidarity: "Any unannounced intertextual reference or allusion poses an understanding test, which can elicit laughter 
and enhance rapport in its own right" (Norrick, 1993, p. 70). There is an interesting parallel here with the use of Allen's (1983) "intertextual codes" of soap interpretation. Though the soap text has not made use of intertextual references, other texts are drawn into the retellings that were not present in the original soap, showing that intertextual codes can be imported in the interpretive process, and that doing so can generate humor.

Almost all of Lyle's humor relies on clever word choices which are woven seamlessly into the telling. In contrast to Margie's, his humor is more often part of the telling than bracketed from it. At the same time, though, his wordplay juxtaposes the reality of the soap with its status as a crafted production and so moves between close and distanced readings for humorous effect.

One of the most distinctive elements of Lyle's humor is his innovative ways of saying simple things. When Carter acts up, Lyle says he "mini-flips." When he stops by to reminisce, Lyle calls it "a stroll down Memory Lane." When Carter goes to Galen's apartment he "transports chez Galen," and when he fantasizes about killing Trevor, Lyle refers to "FutureFlashes." The reference to "transporting" is an intertextual reference to Star Trek and implicitly refers to many previous group discussions about the highly implausible ability of soap opera characters to go from location to location without regard to transportation or time. His term "FutureFlash" refers to a particular video-cinematic code, and so demonstrates his own genre competence while assuming that his readers have enough genre competence to understand the term. Lyle also uses extensive hyphenation to quickly recap storyline developments, describing a "rapidlyunhinged-just-got-fired-from-Tempo Carter" and Carter's " I've-been-dumped-on-toolong ---I-was-framed' mode." Again, this kind of wordplay suggests the fictional construction of the material at the same time it retells it as though it were real, drawing on an incongruity he assumes his sophisticated audience will understand.

Not all of Lyle's wordplay is unique. His use of evaluative nicknames for the characters, for instance, is one of the most popular forms of humor in the group, used in $38 \%$ of all humorous posts. Nickname humor is so prevalent that dictionaries have been compiled and posted for new participants. Some of these nicknames are borrowed from the soap text itself, as is the case with all of Margie's and two of Lyle's, "Mahatma" (for the ex-monk Jeremy) and "Porkchop" (for Trevor). Others originate within the group, and are appropriated by other participants. The nickname "DynaHo" seen here, 
suggests a bawdiness which troubles some of the group's women. His other choices "Psycho" (for Carter) and "Not" (for Natalie) are less controversial.

Nicknames codify interpretations voiced in past discussions. "Not," for instance is an expression of the oft-heard sentiment that the recasting of Natalie was unsuccessful. The new actress, Melody Anderson, said many in the group, was simply "not" Nat. By calling her "Not" this distanced evaluation was inserted into an otherwise close retelling, alluding to the incongruity between telling what happened to "Natalie" while not believing Anderson is her. "Psycho" likewise indexes the group's assessment of Carter as a psychotic. Nicknames work as humor because they so succinctly index the qualities on which other participants have based their interpretations and because they juxtapose the interpretive frame with the soaps' realism. While nicknames are the single most common form of r.a.t.s. humor, Lyle is distinctive both in the extent to which he uses nicknames, and the wide range which only he uses (a phenomenon not captured in this particular excerpt).

Norrick (1993) has argued that wordplay is not invested with evaluations or performer's pasts, and hence does little to present an individualized self. This evidence contradicts that claim. Lyle's wordplay is often evaluative and, because it is so unique within the group, clearly marks him as a distinctive individual. Bakhtin argues that "the better our command of genres, the more freely we employ them, [and] the more fully and clearly we reveal our own individuality in them..." (1986, p. 80). Lyle's ability to play with the soap opera text at the level of syntax is one reason he is seen as a virtuoso within the group.

\section{$\underline{\text { Responsive Humor }}$}

Lexine's post. Both Margie and Lyle's humorous performances are written in direct response to the show's broadcast. Much of the humor on r.a.t.s., however, responds directly to other people's comments on the show. Interestingly, one man, Dan, a regular and long-time poster, consistently stimulates more humorous responses than any other poster. If one combines his own humorous posts with all the humorous posts written in response to his, he emerges as responsible for more humor than any other person in the Carter Jones corpus.

Dan is an updater; his updates, however are fairly straight-forward and less loaded with humor than the two we have seen. He uses the same motif of titles for the storylines that Margie and Lyle do in their updates. In the post below (September 30, 
1992), Lexine picks up on one of his titles, "One of these women is not like the others," applies it to characters other than those for whom Dan created it, and elaborates its Sesame Street origins into a well-orchestrated joke:

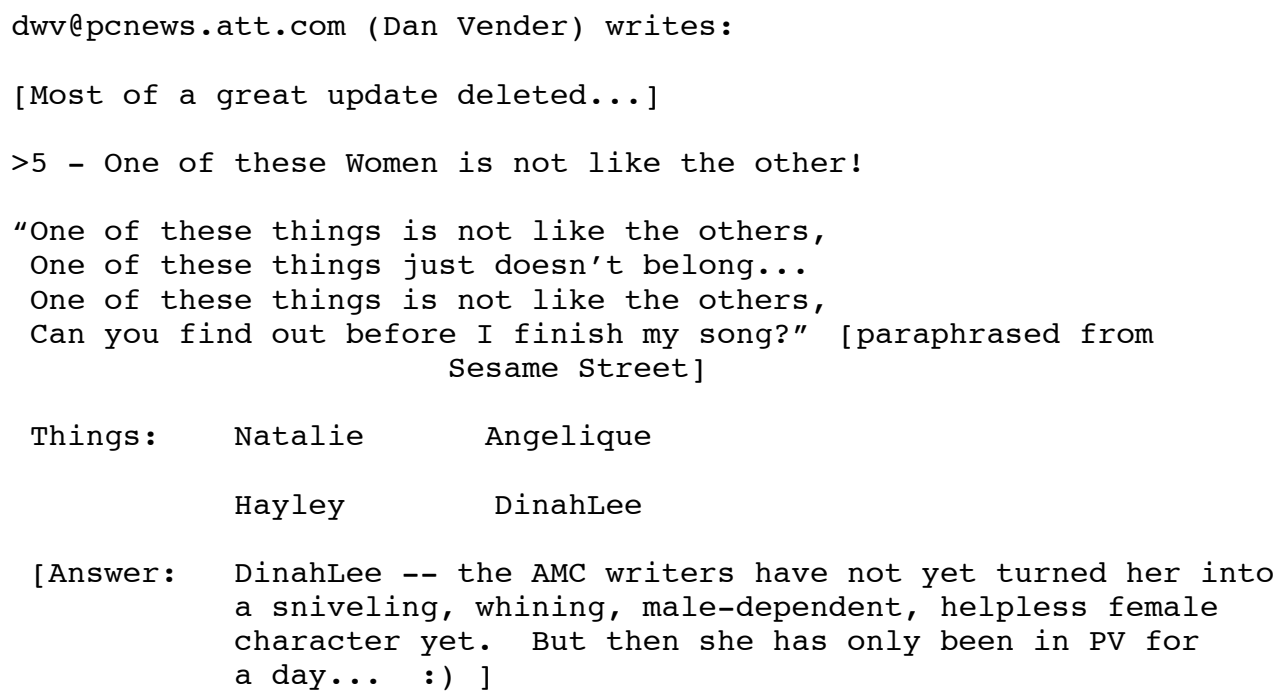

This post, and the one to which it responds, like Lyle's find some of their humor in their intertextual invocation and transformation of another television show. Here Lexine explicitly paraphrases Sesame Street, even using formatting to replicate the appearance of that show's "one of these things is not like the others" game. The use of formatting to frame and invoke humor is not common in r.a.t.s., and her choice to use it here points to the creativity involved in r.a.t.s. humor.

Lexine is highly critical of the show in this post, and directs her criticism explicitly at the writers, who eventually make all female characters "sniveling, whining, male-dependent, [and] helpless." Like Margie does in her update, Lexine invokes the "damsel in distress" theme, much discussed and decried in the group, to provide the punch line. Of course, to get the joke, readers must be invested enough in the characters to recognize the similarities between them. Again, we see humor weaving together close readings of the show with other pop culture texts and the group's previous discourse in a stylistically-individualized manner. The incongruities here are multiple -juxtaposing the soap opera with Sesame Street, the childlike quality of the "one of these things" game with the very adult issue of female dependency, and these women's acceptance of the show with recognition of its flawed portrayal of women. As is the case in Margie's update, each incongruity creates distance from the show, but closeness with 
the other participants who are presumed to share the knowledge and competence to see these flaws.

Another interesting aspect of this post is how it indexes Lexine's status as a mother. Though many who are not mothers are familiar with Sesame Street, Lexine's motherhood has been the subject of much discussion within the group. She told the group when she learned she was pregnant, and used her sig file to count down to the baby's due date. When he was born (a little late), she replaced the countdown with an ascii illustration of a baby. Her reference to Sesame Street thus reinforces her status within the group as a young mother, strengthening her group identity.

Patty's post. Lexine's post is in response to a title in Dan's update. Dan stimulates most of his humorous responses through what he calls "unanswered questions," a set of ten numbered rhetorical questions he appends to the end of each of his updates, or posts alone when he others write the updates. The unanswered questions find most of their humor by pointing out the limits of soap-opera reality (in other words, by evoking critical competencies). In this post, Patty (October 13, 1992), responds to one such set of unanswered questions. I have edited the questions to those relevant to the Carter Jones storyline.

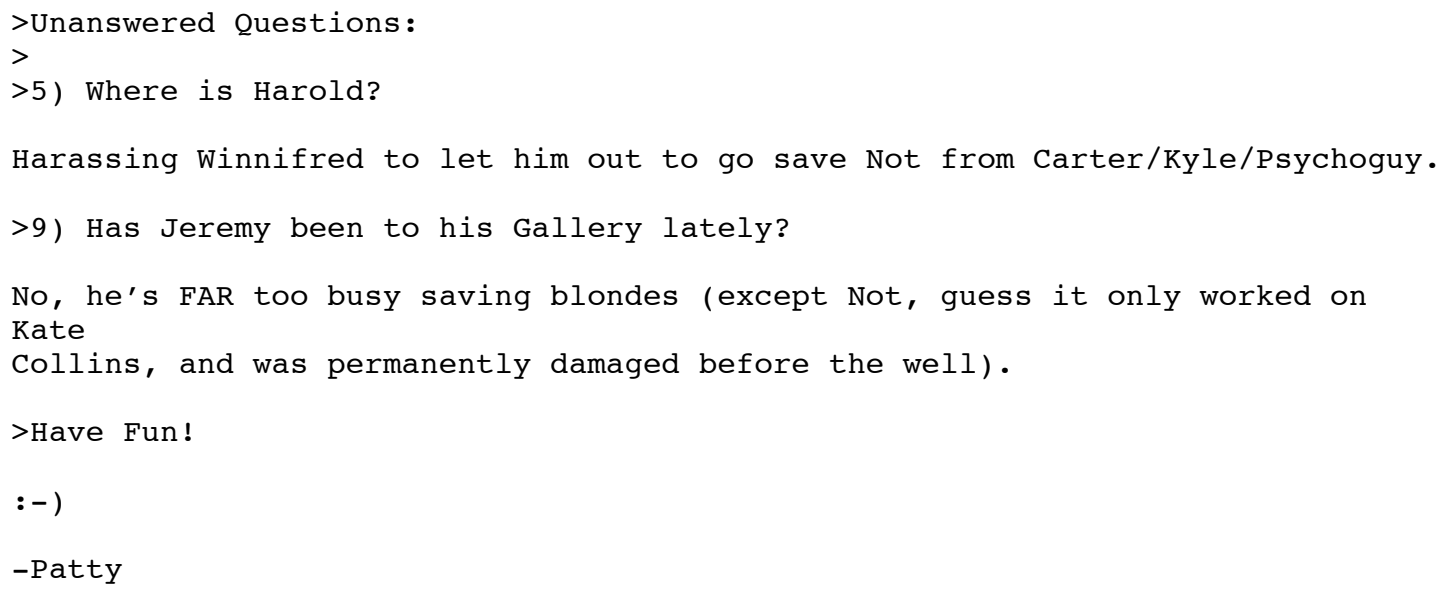

Perhaps the most striking feature of the unanswered questions and their responses is the extent to which they rely on knowledge of the show's characters and past, in other words, how these questions index common understandings unique to AMC fans. Dan's fifth question “Where is Harold?" refers to Timmy's dog. The answer uses a minor character, Winnifred, the maid in Timmy and Harold's home. Harold and Winnifred both occasionally disappear from the show for months on end; Patty is 
assuming her readers will know the show well enough to know who both these characters are and to be entertained by the idea that when they are not on screen they might be together. Patty's response alludes also to Harold's first weeks on the show, in which he did his canine-best to save Natalie from the well. The humor in the thought of Harold wanting to go out and rescue Natalie again relies on this past knowledge. Group membership is often tested through humor's oblique references to shared knowledge. Clearly, if one is able to catch the humor both in these questions and in the responses, one has sizable in-group knowledge.

The humor here also relies on the group's past discussion. As I have already discussed, the well storyline was the topic of a great deal of critical humor. By referring implicitly to the well, Patty is assured that some of her audience will place this humor in an ongoing group tradition. Patty also invokes the "damsel in distress" theme in regards to Natalie, as did both Margie and Lexine. The suggestion that Harold wants to rescue Natalie also reinvokes many past utterances suggesting that Harold, and his owner Timmy, were the smartest characters on the show. Again, Patty's response implies, the dog might be an improvement on the humans.

Dan's ninth question "Has Jeremy been to his gallery lately," likewise relies on and calls forth a response grounded in knowledge of the show and the collective discussion that precedes. At this point in the storyline, Jeremy, a gallery owner, had spent all his waking hours protecting Galen and Dinah Lee (both of whom, like Natalie, are blonde) from Carter. Patty's response that Jeremy is too busy saving blondes invokes yet again the theme of women in need of male rescue, however instead of faulting the writers as Lexine does, she seems to fault the character. She follows this by suggesting that Jeremy's inability to rescue Natalie may be due to the change of actresses; his psychic powers only worked on Kate Collins, the previous Natalie (the distinction between Natalies is also made earlier with her use of the nickname "Not"). She goes from the distanced reading involved here back to a close reading when she adds the qualification that Jeremy was among the many who failed to notice anything amiss when Natalie was being impersonated. This failure of Jeremy's was discussed at the time as people argued that Jeremy had always had a deep bond with Natalie and was psychic, qualities that should have led him to her rescue. In sum, Patty's humor relies on understandings of Jeremy both in terms of the show's past history and in terms of the group's interpretation. Humor is generated by the juxtaposition of close and 
distant frames, while group solidarity is strengthened through references to the soap's past and the group's.

At the end of his unanswered questions Dan invites the others to "have fun." Patty responds with a smile that suggests she has indeed had fun. With these questions Dan has invented and codified a group-specific form of participatory humor. His questions invoke the show's inconsistencies (in this case the disappearances of Harold and of Jeremy's gallery). At his invitation, others use those as spring boards for playing with the show's past and the group's past, combining bits and pieces from that dual history to invoke additional sources of amusement. Again we see that humor in the group reinvokes itself, in so doing codifying the group's interpretation of the show. The humor here further demonstrates how humor creates solidarity in this group by positioning all participants as competent viewers of the genre.

Amy's post. This final performance is also an example of responsive humor. In this case, Amy responds to Margie's complaint about Galen's telephone. As seen in the embedded quotation, Margie uses the critical style of humor we see in her updates, laughing at the show and herself. Amy picks up on her criticisms and uses them to launch her own humorous litany on fundamental absurdities of the soap opera world (August 7, 1992):

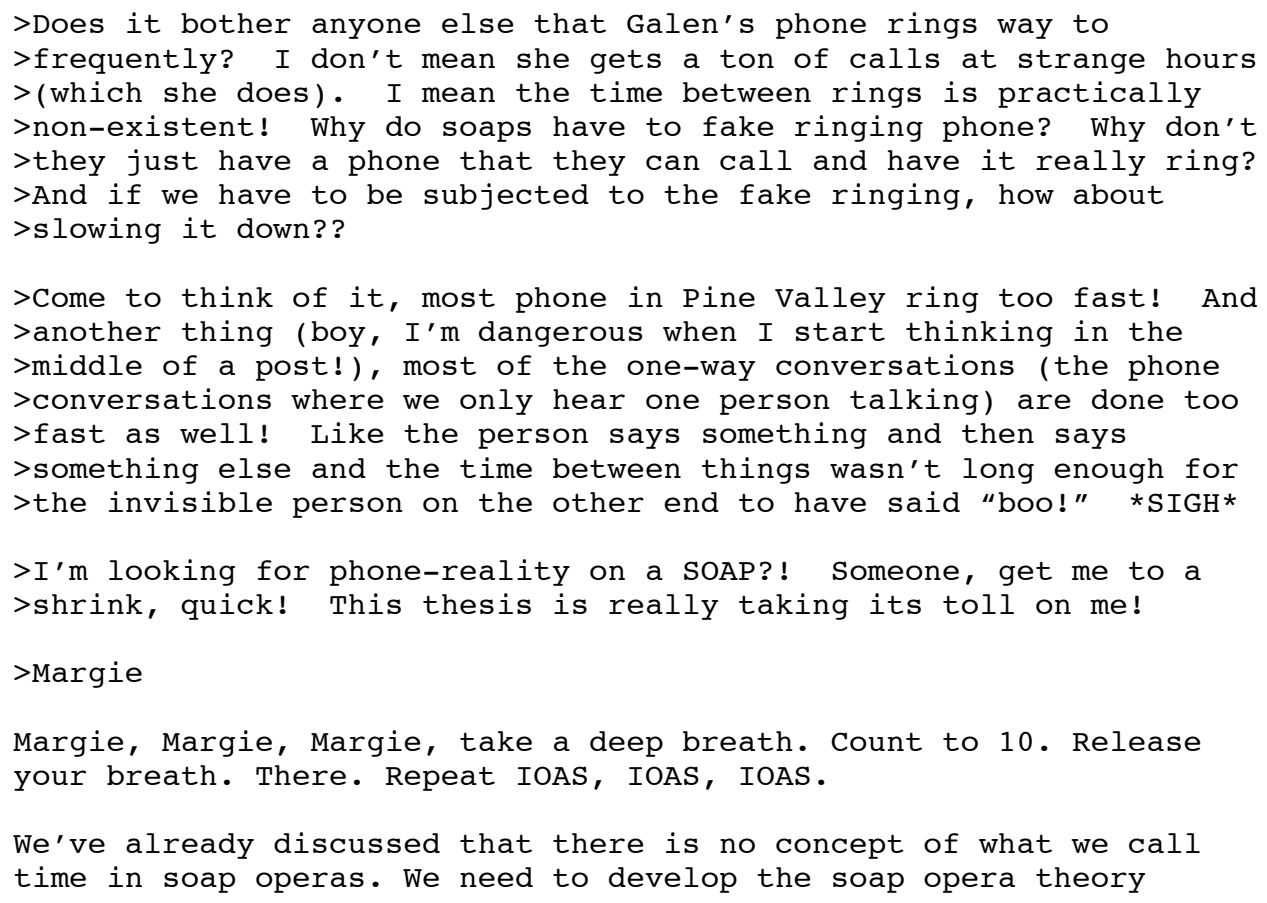




\begin{abstract}
of relativity (SOTOR)--it relates space, time, AND production schedules, writer's quirks, writer's failed memories, last minute plot changes, actors contracts, available sets, available sound effects, etc. It's sort of like cartoon physics. It can be used to explain why Dimitri can ride 20 miles on a horse in the same amount of time it takes Erica to get there by car, and why the next day Brooke and Edmund can walk to the same place, why mail arrives before it was sent, and why the phones ring too fast. In fact, maybe this is the answer to the PVGD problem too. With all of these people zipping around faster than the speed of light, it's no wonder that they're aging faster than normal. Of course, that doesn't explain why it doesn't affect the adults...we'll have to look into a corollary for that.
\end{abstract}

Amy begins with a reminder to Margie "IOAS," an acronym for "It's Only A Soap." The phrase has been conventionalized in the AMC discussion to the point where its meaning need rarely be spelled out. It is used like a mantra to invoke calm in the face of hopeless soap opera absurdity, as Amy's full comment clearly shows, "take a deep breath. Count to 10. Release your breath. There. Repeat IOAS, IOAS, IOAS". "IOAS" indexes many interesting aspects of this group's collective stance to the show, in particular their recognition that the show is only a constructed fiction, but one to which they are legitimately attached. The show, says this acronym, is meant to be a source of pleasure; when it's not pleasing, one should distance one's self from the show instead of getting upset. "IOAS" negates irritation over the show, at the same time validating one's right to irritation. The fact that the phrase has been conventionalized indicates for all that everyone finds themselves annoyed by the show. "IOAS" thus represents the fundamental incongruity of being a soap opera fan, and does so in an way distinctive to this group, thus enhancing solidarity.

The critical sentiments behind "IOAS" are often channeled into humor, as we've seen and as Amy demonstrates here. She categorizes Margie's complaint about the ringing of the telephone as one of a type voiced often within the group. She makes explicit the link between this complaint and past group discourse by reinvoking AMC absurdities "we've already discussed," a comment which also makes explicit the group's commonality in the plural subject "we." She draws parallels between the telephone ring speed, the distance to Dimitri's hunting lodge, the time warp that surrounds mail, and "PVGD" (a group acronym for Pine Valley Glandular Disorder, the illness which explains why $A M C$ children age far faster than real people). Her reference to the incongruity between Dimitri's and Erica's abilities to reach the hunting lodge echoes Lyle's use of the term "transports." "PVGD," beautifully demonstrates the codifying value of humor by demonstrating, like "IOAS," how much this has been 
discussed. This particular rapid-aging phenomenon is so much a part of soap opera reality / absurdity that it is granted similar acronym status elsewhere in soap opera fandom. The weekly tabloid Soap Opera Weekly, for instance, uses the phrase "SORAS," meaning "Soap Opera Rapid Aging Syndrome."

Amy goes beyond listing these similar suspensions of soap opera realism to explaining these phenomena with "the soap opera theory of relativity (SOTOR)" which relates space and time in Pine Valley to a sophisticated survey of the realities of soap opera's construction: "production schedules, writer's quirks, writer's failed memories, last minute plot changes, actors contracts, available sets, available sound effects, etc." Amy's immediate proposal of an acronym for her theory (SOTOR) makes fun of the group's fondness for acronyms.

Amy's post demonstrates many of the phenomena seen in the other humorous performances above. She selects resources from across the soap opera text and past discussion and transforms criticism into entertainment, juxtaposing realism and absurdity, entertainment and frustration. She draws on the incongruities between close and distanced readings. In so doing, she strengthens the group's collective interpretation and enhances the closeness between participants. The choices of resources and the stances she takes are her own, thus the process of combination and transformation also individualizes Amy.

\section{Discussion}

As is the case in other groups, humor in r.a.t.s. facilitates self presentations, common understandings, group solidarity and identity and discussion of problematic aspects of the social world. Two things are distinctive about humor in the context of r.a.t.s., however, and bear further discussion. First, these phenomena take place in direct relationship to a pre-existing narrative, the soap opera, and it is in the play between that narrative and the group that the humor arises. Second, this humor is being used in computer-mediated communication, where mechanisms of framing performance, and creating self-presentation, group solidarity and group identity are more problematic than they are in non-mediated situations.

\section{Humor, Incongruity and the Soap Opera Narrative}

I began with the claim that r.a.t.s. humor arises in the incongruities between close and distant readings of the soap opera, both of which are encouraged by the genre's 
form. Evidence for this is seen in almost all of the humorous posts I have analyzed. Margie's update moves between a dramatic retelling of the events which positions both her and her readers close to the narrative. Her use of evaluative elements such as exclamation points, quoted speech, capitalization and others all serve to bring her readers closer to the story. In contrast to this are her bracketed comments which step back and criticize the same story she is retelling with such close detail. It is the juxtaposition of the critical comments with the close retelling that marks her comments as humorous and lends them their humorous force. Though it is not as critical, Lyle's update also moves between close, detailed dramatic retelling, filled with quoted speech and other evaluative emphasis, and more distanced viewing, as seen in his use of nicknames, hyphenated summaries, and insertion of intertextual references. Lexine's "one of these things" games assumes the readers care for the characters well enough to know them, yet turns that closeness around to point out that the writers are to be faulted for their weakness. The distant view of "writers" is juxtaposed with the close analysis of characters. Patty's answers to the unanswered questions also assume close familiarity with characters and story history, suggesting closeness to the text, but then turn that closeness to humor by highlighting the story's status as a constructed fiction. This incongruity is seen in its fullest form in Amy's "SOTOR," which stands so far back from the narrative that all of its absurdities come together into one explanation -- soap time is relative. This theory means little, however, if readers aren't engaged closely enough with the text to find things annoying.

Humor in r.a.t.s. thus functions to transform the most problematic element of being a soap opera fan -- loving the show while recognizing its many shortcomings -into a source of entertainment rather than irritation. It is this transformative quality of humor which provides it with its social power to create and enhance participant solidarity and group identity. One way in which it does this is by positioning all the group members as highly knowledgeable and competent readers of the genre. Readers are assumed to have a detailed awareness of soap opera events and characters both recent and historical. Without this, references to Winnifred or Harold's absences (as seen in Patty's post), to Trevor needing a clue "AGAIN," or to "the hunting lodge" make no sense.

Humorous posters also presume that the others in the group understand the production of soap operas, recognizing the ways in which they are constructed and the forces that shape their final form. Readers are taken to be intelligent, capable of seeing 
all of the show's flaws. In short, humorous performers treat their audience as savvy experts, generating solidarity through this positive appraisal of one another, and generating a group identity as sophisticated critical fans.

That they are "fans" despite their sophisticated criticism is also a source of solidarity and group identity in this group. Humor is one way in which participants negotiate what it means to be a soap fan, and encourage one another's continued involvement with the genre despite its flaws. This is seen in the ways their humor questions and pokes fun at their own relationship to the genre. The relationship is a complex one, as the phrase "IOAS" indicates. The participants all care about the show, they are all invested in it, and they all respect this in one another. This is clear in the amount of time and energy exerted in contributing viewpoints to the ongoing discourse. At the same time, the soap opera regularly falls short of what they would like: the storylines are flawed, the acting poor, the writing inconsistent, the props cheap. Perhaps above all, the realism on which soaps depend may be too hard to buy. At such times, the show is a source of annoyance, rendering the status of the intelligent fan problematic. Henry Jenkins argues this is a common phenomenon in fan cultures and that it often leads to fan creativity, writing:

The fans' response typically involves not simply fascination or adoration but also frustration and antagonism, and it is the combination of the two responses which motivates their active engagement with the media. Because popular narratives often fail to satisfy, fans must struggle with them ... because the texts continue to fascinate, fans cannot dismiss them...but rather must try to find ways to salvage them for their interests. (1992, p. 23)

With critical humor, r.a.t.s. participants assert their mastery over the soap opera. By laughing at the show, the participants are able to distance themselves from it, but in a way which encourages continued involvement. These posters describes how r.a.t.s. humor enhances or encourages involvement with the show by transforming faults to fun:

The people posting here are _hilarious_. It's nice to find a bunch of people who watch soaps for the reason I do -- they're funny (in particular at their most serious) (Samantha, October 1, 1993) 
I enjoy reading it because the folks are so creative. I find it greatly enhances my watching of Days and AMC, because I find more humor in it than I did in my pre-r.a.t.s days. (Sandra, October 5, 1993)

The humor offered by the discussion may even be the only reason fans remain engaged during periods when the soap is particularly bad:

when one of my soaps gets dull, the net will keep me watching--eg. the song about Nat in the Well (AMC), funny updates, fun stuff period (Zoey, December 1, 1991)

By transforming a dull, overly-serious or absurd drama into a source of humor, these fans remind one another that it is okay to pick apart the show, that there are ways to be a fan despite its shortcomings, and that they are all caught in this bind between enjoyment and irritation.

A final way in which humor's transformation of close to distant readings facilitates group solidarity is that it positions the savvy experts of the group in opposition to the soap opera writers, creating an "us vs. them" dynamic which inherently defines participants as an in-group. The humor often refer to the writers explicitly, usually blaming them for the show's flaws and suggesting that they underestimate their viewers. By taking mastery of the soap through humor, the fans affirm that they are smarter than the writers, and smarter than the writers take them to be.

Humor's alignment with distant readings is also at the heart of its ability to facilitate self-presentation. Soap narratives are structured to lend themselves to multiple interpretations, meaning viewers are likely to have different takes on the same material. Furthermore, whether they infer the same narrative implications or not, viewers are likely to have different criticisms. Critical and interpretive humor is thus highly individualized, as each humorist brings their own perspective to bear on the show. Humor and the Establishment of Group and Identity in CMC

The qualities of soap opera humor I have just discussed would be true in any fan group, whether computer-mediated or not. The computer-mediated quality of this group, however, problematizes some of these humorous functions and exaggerates others. In this section I consider the significance of this humor in the computer- 
mediated context, discussing how it is framed and how its facilitation of solidarity and individuality enables participants to overcome the seeming anonymity and geo-spatial separation of the medium.

Very little, if any, of the humor in r.a.t.s. is framed through conventionalized openings. Indeed, very little of it is conventionalized into formal cues. There are, however, some systematic ways in which a frame shift toward humor is indicated, though they are not unique to framing humor. The use of square brackets is one such cue. Other such conventionalized ways of marking humor include punctuation, capitalization, extension of letters, formatting, and repetition. In some cases, such as unanswered questions and their responses, nicknames, and some acronyms, particular forms of humor have been conventionalized. In other cases humor arises in the content itself through the incongruous juxtapositions created rather than through formal features.

R.a.t.s. humor is responsive to other's posts in at least two ways. Humor more often than not occurs in explicit reactions to other's messages, and humor often invokes past group discussions. Humor is thus one of the ways in which participants blend the group's discourse into a unified whole. What could be an ongoing stream of messages with little coherence are transformed into group history and interpersonal contacts. This does not happen in all Usenet groups, and may be one reason other groups do not develop the sense of community found in r.a.t.s. Furthermore, by incorporating previous r.a.t.s. voices into their humor, the performer makes the audience collaborators. The humor is a joint production, which the audience not only understands but helps create. This joint authorship enhances group identity and solidarity.

The humor here also shows that the solidarity of computer-mediated groups can be enhanced through references to common knowledge, including knowledge of the soap, of other pop culture texts (e.g. Star Trek, The Twilight Zone, Sesame Street) and of the group's previous discourse. The continual invocations of common knowledge assumes that the others are familiar with these things and accordingly strengthens the shared bases on which group unity is founded.

Computer-mediated groups can create solidarity through developing interpretive consensus. Because humor relies upon shared meanings and its appropriateness depends upon shared interpretations, humor can be a particularly 
effective mechanism for doing this in CMC. Much of the humor in r.a.t.s. involved recycling interpretations which had already been voiced, such as the notion that women should not be portrayed solely as victims. New interpretations which ring true (e.g., Claudette's first use of "Not") are transformed into collective interpretations as they are reinvoked, extended and transformed by subsequent posters. Those meanings which are repeatedly raised in service of humor are continually reinvested with the powers to entertain and to symbolize the group's shared interpretations. As is the case with "Not" and with the unanswered questions, humor can lead to codified forms of group-specific meanings, and these codes can serve the role that artifacts might serve in face-to-face groups, providing central objects around which the group can define itself.

Perhaps one of the most important ways in which humor can enhance solidarity in the CMC context is by creating a friendly social context despite the impersonal elements of the medium. John Morreall argues that "sharing humor with others, then, is a friendly social gesture. It shows our acceptance of them and our desire to please them...[humor] set[s] up the mood of acceptance and make[s] the other person relax" (1983, p. 115). One poster comments that she reads r.a.t.s. because "the people are warm, funny, and a nice group" (Jamie, Oct 1, 1993), suggesting both how humor helps define a group identity and makes that group appealing.

Humor also serves as a means of creating individuality when the cues we use to define ourselves in face-to-face groups are unavailable. One simple way this happens is through self-references, as seen especially in Margie's posts where she shifts from storytelling voice to her own voice by interjecting the pronouns " $\mathrm{I}$ " and "me," explicitly reminding the readers that there is a person there. Kamberelis and Scott, drawing on Bakhtin, suggest that individuality "gets defined in and by the effects of appropriating, transforming, and resisting particular discursive practices in particular ways" (1992, p. 373). We see just this process in the humor in r.a.t.s. Other voices in the soap opera, other popular cultural genres, the r.a.t.s. community, and communities outside of this circle are appropriated, transformed, and resisted in individualized ways. Lexine's post exemplifies this process. She appropriates the voice of Dan, quoting him explicitly. He, of course, has appropriated voices from Sesame Street and transformed them to work with those of the soap opera. Lexine re-appropriates the Sesame Street reference, transforms it, further incorporating voices from $A M C$, and uses the whole to resist the $A M C$ text, criticizing the ideological agenda in the writer's representation of women, a criticism that reinvokes numerous voices in the community who have made that 
complaint as well. What is her own is the choice of other voices, the affective reaction to them, and the creativity with which she combines these voices into her own perspective. Humor is not the only way this transformation of voices into an individual voice occurs in CMC, but it is a significant one.

Finally, humor has particular power in CMC to define individuality because it is performative. Bauman has written that performance has special potential to increase the status of the performer:

Through his performance, the performer elicits the participative attention and energy of his audience, and to the extent that they value his performance, they will allow themselves to be caught up in it. When this happens, the performer gains a measure of prestige and control over the audience -- prestige because of the demonstrated competence he had displayed, control because the determination of the flow of the interaction is in his hands. (1975, p. 305)

Virtuoso humorous performance is inseparable from status in r.a.t.s., as seen in the posters singled out as successful by survey respondents. This was demonstrated above in Brian's description of a good poster as being one like Lyle and Granma. Here Laurie puts Brian (who has a long Polish surname) in that same class:

As I said, Lyle is great! There are a lot of really funny people who post to AMC r.a.t.s. Anne and Brian PRZOIUHIHPIHOIHPOI (well you get the idea) are funny too. (November 27, 1991),

Humor creates and transforms the social structure of the community. It is in part through humorous performance that particular posters overcome the seeming anonymity of the computer medium to develop their own voices. In an ongoing parade of screens of posts which look nearly identical, strong individual voices emerge, gaining recognition, status and enhanced power to shape group consensus. The extent to which these voices become recognized is a measure of their skill in creatively reworking the available cultural resources and of their power in shaping the group's interpretive consensus.

However, there are boundaries to how distinct an individual's voice ought to be. The negative reaction to Lyle suggests that there are mixed sentiments on the value of individuality compared to the value of community, and of the value of humor compared with that of solidarity. Some dislike him because he consistently sets himself 
apart from the others with minor things like a copyright logo and larger things like correcting other's assessments. Others, in contrast, either don't find those things disruptive, or feel that the worth of his humorous contributions outweigh them.

\section{Conclusion}

The humor in this group raises many more interesting issues for analysis than are developed here. For instance, one could develop the ways in which this humor results from the dominance of women in the group or the gendered issues raised by the soap opera. One could analyze the ways in which popular culture is appropriated through intertextual references. One could provide a more detailed explanation of the many complex ways of relating to the soap opera which I have glossed as "close" and "distant" reading. However, I approached this material with a specific purpose, which was to show how humor in r.a.t.s. functioned to create group solidarity, group identity, and individuality as it negotiated the problematic elements of being a soap opera fan.

My analysis is a response to constructions of computer-mediated communication as a socially-impoverished domain. I have shown here how one group creates social life through the medium, and the privileged role of humorous performance in that process. Because humor relies on group norms, knowledge, practices, and problems, it provides a way to deal with problematic issues within the group, to generate unique identities and to create group identity and solidarity. Though this study has looked at only one group, it has implications for other work on computer-mediated communication.

One implication is that humor can be a particularly important locus of social formation in the computer-mediated context. Given that so many identity and groupdefining cues are stripped in this text-only medium, discourse practices gain enhanced force to create social meaning. Because humor simultaneously indexes so many important social domains, it has particular power to affirm the group's self-definition and to transform its social structure. Future analyses of computer-mediated groups should consider the extent to which they use humor and the ways humor operates. Rich comparative analyses of humor (or the lack of humor) across a range of computermediated groups can provide unique insights into the dynamics of CMC social formation.

Furthermore, the importance of the topic under discussion is evident from this analysis of humor. It is in this group's dynamic engagement with soap operas that 
humor emerges, and it is specific features of the soap genre that shape the group's concerns and the purposes they invoke humor to serve. R.a.t.s. humor is a way to grab hold of the soaps and rework them to meet the needs of a critical and sophisticated audience. The group's identities and sense of solidarity also emerge in direct relationship to the topic under discussion. This demonstrates that computer-mediated communication cannot be understood as a unified field. The computer medium is only one of many influences on on-line groups. Social processes in computer-mediated groups, including performance and humor, are deeply rooted in specifics, including topics of discussion and purposes. Future work on CMC must attend to the detailed contexts in which a given group's behavior is grounded. 


\section{References}

Allen, R. C. (1983). On reading soaps: a semiotic primer. In E. A. Kaplan (Ed.),

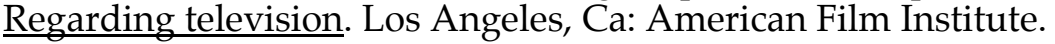

Allen, R. C. (1985). Speaking of soap operas. Chapel Hill, NC: University of North Carolina Press.

Ang, I. (1985). Watching Dallas: Soap opera and the melodramatic imagination. New York, NY: Routledge. Press.

Bakhtin, M. M. (1981). The dialogic imagination. Austin, TX: University of Texas

Bakhtin, M. M. (1986). Speech genres \& other late essays. Austin, TX: University of Texas Press.

Bauman, R., \& Briggs, C. L. (1990). Poetics and performance as critical perspectives on language and social life. Annual Review of Anthropology, 19, 59-88.

Bauman, R. (1971). Differential identity and the social base of folklore. Journal of American Folklore, $\underline{84}$, 31-41. 311.

Bauman, R. (1975). Verbal art as performance. American Anthropologist, 77, 290-

Baym, N. (1994). Communication, interpretation, and relationships: A study of a computer-mediated fan community. Unpublished doctoral dissertation, University of Illinois, Urbana-Champaign, IL.

Baym, N. (1993). Interpreting soap operas and creating community: Inside a computer-mediated fan culture. Journal of Folklore Research, 30, 143-176.

Brown, M. E. (1994). Soap opera and women's talk. Thousand Oaks, CA: Sage.

Cheseboro, J. W., \& Bonsall, D. G. (1989). Computer-Mediated Communication: Human relationships in a computerized world. Tuscaloosa: University of Alabama Press.

Chiaro, D. (1992). The language of jokes: Analysing verbal play. London: Routledge.

Danet B., Wachenhauser T., Bechar-Israeli H., Cividalli A.,\& Rosenbaum-Tamari, Y. (1995). Curtain Time 20:00 GMT: Experiments in Virtual Theater on Internet Relay Chat. Journal of Computer Mediated Communication, 1(2).

Ferrara, K., Brunner, H., \& Whittemore, G. (1991). Interactive written discourse as an emergent register. Written Communication, 8, 8-34. 
Fox, W. S. (1983). Computerized creation and diffusion of folkloric materials. Folklore Forum, 16, 5-20.

Hobson, D. (1989). Soap operas at work. In E. Seiter, H. Borchers, G. Kreutzner, \& Warth E. (Eds.), Remote control: Television, audiences, and cultural power (pp. 150167). New York, NY: Routledge.

Hymes, D. (1986). Models of the interaction of language and social life. In J. J. Gumperz, \& D. Hymes (Eds.), Directions in sociolinguistics: The ethnography of speaking (pp. 35-71). New York, NY: Basil Blackwell.

Jenkins, H. (1992). Textual poachers: Television fans and participatory cultures. London: Routledge.

Jindra, M. (1994). Star Trek fandom as a religious phenomenon. Sociology of Religion, 55, 27-51.

Kamberelis, G., \& Scott, K. D. (1992). Other people's voices: The coarticulation of texts and subjectivities. Linguistics and Education, 4 , 359-403.

Kiesler, S., Siegel, J., \& McGuire, T. W. (1984). Social psychological aspect of computer-mediated communication. American Psychologist, 39 , 1123-1134.

Labov, W. (1972). The transformation of experience in narrative syntax. In W. Labov, Language in the inner city: Studies in the black English vernacular (pp. 354396). Philadelphia: University of Pennsylvania Press.

Liebes, T., \& Katz, E. (1989). On the critical abilities of television viewers. In E. Seiter, H. Borchers, G. Kreutzner, \& Warth E. (Eds.), Remote control: Television, audiences, and cultural power (pp. 204-222). New York, NY: Routledge. New York.

Morreall, J. (1983). Taking laughter seriously. Albany, NY: State University of

Mulkay, M. (1988). On humour: Its nature and its place in modern society. Cambridge, UK: Polity.

Myers, D. (1987). "Anonymity is part of the magic": Individual manipulation of computer-mediated communication contexts. Qualitative Sociology, 19, 251-266.

Nilsen, D. L. F. (1993). Humor scholarship: A research bibliography. Westport, CT: Greenwood Press.

Norrick, N. R. (1993). Conversational joking: Humor in everyday talk. Bloomington: Indiana University Press. Kentucky.

Oring, E. (1992). Jokes and their relations. Lexington: University Press of

Palmer, J. (1994). Taking humour seriously. London: Routledge. 
Polanyi, L. (1982). Linguistic and social constraints on storytelling. Journal of Pragmatics, 6 , 509-524. MIT.

Raymond, E. S. (Ed). (1991). The New Hacker's Dictionary. Cambridge, MA.:

Reid, E. (1995). Virtual worlds: Culture and imagination. In S. Jones (Ed.), Cybersociety: Computer-mediated communication and community (pp. 164-183). Thousand Oaks, Ca: Sage.

Rheingold, H. (1993). Virtual Communities. Reading, MA: Addison- Wesley.

Seiter, E., Borchers, H., Kreutzner, G., \& Warth E. (1989). "Don't treat us like we're so stupid and naive": Towards an ethnography of soap opera viewers. In E. Seiter, H. Borchers, G. Kreutzner, \& Warth E. (Eds.), Remote control: Television, audiences, and cultural power (pp. 223-247). New York, NY: Routledge.

Sproull, L., \& Kiesler, S. (1991). Connections: New ways of working in the networked organization. Cambridge, MA: MIT Press.

Walther, J. B., \& Burgoon, J. K. (1992). Relational communication in computermediated interaction. Human Communication Research, 19, 50-88.

Wilkins, H. (1991). Computer talk: long-distance conversations by computer. Written Communication, 8 , 56-78. 